\title{
Resistance patterns and genetic variations in patients with hepatitis $C$ virus: emerging role of telaprevir
}

This article was published in the following Dove Press journal:

Virus Adaptation and Treatment

5 June 2010

Number of times this article has been viewed

\section{Argentini \\ D Genovese \\ S Catone}

Istituto Superiore di Sanità, Department of Therapeutic Research and Medicine Evaluation, Rome, Italy

Correspondence: C Argentini

Istituto Superiore di Sanità, Department of Therapeutic Research and Medicine Evaluation, viale Regina Elena 299,0016I Roma

Email claudio.argentini@iss.it

\begin{abstract}
High genetic variability is a characteristic of hepatitis $\mathrm{C}$ virus (HCV) infection: infinite virus isolates are classified into six genotypes plus an emerging seventh one, and an indefinite number of subtypes. The variability is directly connected to the environmental adaptation of infective agents or to the change induced by antiviral therapies. During therapy, wild type isolates are substituted by resistant mutants that are able to maintain the infection. The standard therapy (pegylated interferon [PEG-IFN] and ribavirin) only partially eradicates HCV infection. However, particularly in genotype 1 infection, the rate of uncured patients remains high (between $50 \%$ and $60 \%$ ). Specifically targeted antiviral therapies for HCV infection (STAT-C) consist of developing new antivirals aimed at blocking the virus proteins involved in different replication steps. Telaprevir is an anti-NS3-NS4 protease in phase III trials and represents a promising therapy, especially when associated with PEG-IFN and ribavirin. In vitro and in vivo research studies describe mutations that confers resistance to telaprevir in NS3-NS4 protease (V36A/M/L/G, F43, T54A, R130K, R155L/K/T/Q, A156T/S/V, V170A and Q195K). The emergence of these mutations describes the adaptation capability of $\mathrm{HCV}$ infection.
\end{abstract}

Keywords: HCV, telaprevir, resistance, antiviral therapy, virus adaptation

\section{Introduction}

Hepatitis $\mathrm{C}$ virus (HCV) infects more than 170 million people world-wide and it is the main infective agent in chronic hepatitis, cirrhosis, and hepatocellular carcinoma; the impact of infection is expected to increase in the next 20 years. ${ }^{1-3}$ The standard current therapy for $\mathrm{HCV}$ infection is pegylated interferon (PEG-IFN) and ribavirin. ${ }^{4-6}$

$\mathrm{HCV}$ is highly variable, with six different genotypes, which have less than $72 \%$ homology at the nucleotide level, with multiple subtypes of $80 \%$ to $85 \%$ similarity. Isolates within each subtype are also extremely variable, with $0 \%$ to $12 \%$ divergence among isolates from different patients..$^{7-11}$ A seventh genotype has recently been proposed. ${ }^{12}$ Viral genetic variability contributes to differences in response to therapy because different genotypes respond to therapy at different rates; genotype 2 responds to 6 months' therapy over $80 \%$ of the time, while response in genotype 1 is about $50 \%$ after 12 months' treatment. ${ }^{5,13-15}$ Differences in viral genetic variability in discrete protein regions have also been linked to differences in response to therapy. ${ }^{16,17}$

Recently, the research studies for HCV infection therapy have used the so called specifically targeted antiviral therapies for HCV infection (STAT-C), based on the role played by HCV proteins during the replication. NS3-NS4 protease has been identified 
as a target after definition of its tertiary structure, and a promising molecule, telaprevir, is currently in the clinical development stage. ${ }^{18}$

In this review, through a model of the virus response to telaprevir therapy, we describe the resistance of $\mathrm{HCV}$ infection to treatment with telaprevir.

\section{Genome variability: strength and weakness of $\mathrm{HCV}$}

RNA virus genomes mutate at a high rate. The combination of a lack of proofreading by the RNA-dependent RNA polymerase and a high level of viral replication is responsible for the resulting genetic polymorphism in HCV that defines a classification in clades, genotypes, subtypes, isolates and quasispecies. ${ }^{15}$ Moreover, the error-prone polymerase and the high replication rate (up to 1012 viral particles per day) result in high genomic variability. ${ }^{19}$ For HCV it has been estimated that 1 mutation is introduced per genome per replication cycle. ${ }^{20}$ The bulk of this mutated genome is then eliminated, when the mutation introduces a disadvantage to the virus, or fixed when the mutation is neutral or advantageous. However, infinite variants circulate in infected individuals at any one time. New selective pressures are continuously introduced, especially those produced by the immune system. The pressures select the best-adapted variant. This variant is, therefore, defined as the predominant variant and represents the most common genome species circulating in the host at a specific moment during the infection. Changing the selective pressures means changing the predominant variant. ${ }^{16}$

Antiviral therapy represents a selective pressure in an infected host. The viral population can adapt to and survive the therapy if one or more variants can overcome the effect of the antiviral therapy on virus replication. The variants can be present in the population or arise from a mutation. This phenomenon is known as drug resistance. The resistant variant substitutes the predominant wild type species.

The viral load is an indirect measure of replication efficacy. A well-adapted variant replicates effectively and produces a multitude of virus particles (with at least one genomic mutation) in each replication cycle. Through the concept of suitability, virus adaptation in a host directly associated with survival can be measured. A fit virus is able to replicate efficiently, producing a large number of progeny and resisting selective pressure. Drug resistance can reduce the virus functionality and, as a consequence, the replication rate and the viral load. In other words, drug-resistant mutants are usually less fit than wild type variants. If the virus variability does not introduce resistance mutations or the mutant fitness is too low, the therapy can eradicate the virus. However, it is possible to eradicate the virus by combining more antivirals, especially directed to different virus functions. In such a case, the introduction of multiple-resistance mutations for each antiviral can result in non-functional genomes, the so-called "error catastrophe". These genomes do not produce progenies. Error threshold is defined as the limit of mutability after which the virus genome falls in the error catastrophe. Hence, the error threshold is the primary aim for all antiviral therapies. ${ }^{16}$

\section{Telaprevir}

Telaprevir is a specific inhibitor of the NS3-NS4 protease, specifically developed on the basis of the molecular structure of HCV. ${ }^{19}$ Telaprevir, also known as VX-950, is a peptidomimetic that resembles the $\mathrm{HCV}$ polypeptide which is cleaved by the viral protease. However, telaprevir has an electrophilic "serine-trap warhead" that forms a covalent bond with the catalytic serine residue of the protease, blocking its activity. Telaprevir produces a relevant reduction in $\mathrm{HCV}$ replication both in cell cultures and in animal models. ${ }^{19}$ In the genotype $1 \mathrm{~b}$ replicon system, telaprevir showed potent antiviral, synergistic and sustained effects, in combination with PEG-IFN. The combination suppressed the emergence of resistant variants. ${ }^{21}$ In HCV patients chronically infected with HCV, short-course treatment ( 1 to 2 weeks) with telaprevir rapidly lowered HCV RNA levels by 2 to $5 \log _{10}$ $\mathrm{IU} / \mathrm{mL}$. The combination of PEG-IFN and ribavirin improved the results, but the short-course regimen was coincident with rebound and resistance emergence whereas the longer treatment (24 weeks) gave an important response in 8 out of 12 patients. In this trial the adverse events were limited and well tolerated. ${ }^{22-24}$

The Phase II trials (PROVE, Protease Inhibition for Viral Evaluation, 1 and 2) were conducted on genotype 1 patients in the United States (ClinicalTrials.gov number, NCT00336479) ${ }^{25}$ and Europe (NCT00372385). ${ }^{26}$ Combination of telaprevir, PEG-IFN and ribavirin for 12 weeks, followed by 12 more weeks of PEG-IFN and ribavirin administration has given significant improvement, with sustained virologic responses of $61 \%$ and $69 \%$, respectively. These Phase II trials indicate that the combination can successfully control the infection of genotype $1 \mathrm{HCV}$ isolates, but the increased side effects induced mean that appropriate regimens that are able to reduce therapy costs and improve patient quality life need further investigation. It should be stressed that adverse events increased significantly in both PROVE trials; rash and pruritus in particular were frequent. Approximately $5 \%$ of telaprevir-treated patients 
interrupt therapy owing to adverse events. Regression of these adverse events was observed after suspension of telaprevir. Also decreased hemoglobin levels were frequent. ${ }^{25,26}$ The combined treatment ameliorates liver inflammation. ${ }^{27}$

\section{Resistant pattern to telaprevir}

Variants resistant to telaprevir were identified and characterized early in vitro. ${ }^{21}$ The replicon system, based on a genotype $1 \mathrm{~b}$ isolate, under intense treatment showed an increase in mutations in position 156 of the NS3 protease domain and substitution of alaline with serine (A156S), valine (A156V), or threonine (A156T). These three substitutions act directly on the enzyme pocket, avoiding the covalent interaction of telaprevir, regardless of the different chemical features of the introduced amino acids. The variants were less fit than the wild type. ${ }^{28,29}$

Initial in vivo data collected during telaprevir monotherapy confirmed the early results and contributed to the description of five new mutations (V36A/M, T54A, and $\mathrm{R} 155 \mathrm{~K} / \mathrm{T}$ ) and double mutations, $36+155$ and $36+156$, resulting in variants more resistant to telaprevir. ${ }^{30}$ On the basis of replication in replicon cells and enzymatic activities, the authors define the variants as low resistance (V36A/M, T54A, R155K/T and A156S) and high resistance (A156V/T and double mutants). Low-resistance variants, sometimes preexisting, become predominant during the treatment. On the contrary, high-resistance variants are exclusively and rarely found at the end of therapy (14 days). ${ }^{30}$ Data on mutations 155,36 and 54 were confirmed by analyzing the tertiary structure of the NS3-4 protein. ${ }^{31,32}$ Of great importance, mutations in arginine 155 are described only in genotype 1a, whereas in genotype $1 \mathrm{~b}$ the variants R155T were disadvantaged by the requirement for a double nucleotide substitution $\left(\mathrm{CGG}^{\mathrm{R}}\right.$ to $\mathrm{CCG}^{\mathrm{P}}$, then to $\mathrm{ACG}^{\mathrm{T}}$, probably by a telaprevir-sensitive intermediate with proline in position 155). Also the V36A variant was exclusively described in genotype 1a in vivo. ${ }^{31}$

The short-term combination of telaprevir and PEG-IFN and ribavirin results in control of wild type and mutants, confirming in vitro data in which all NS3-4 protease mutants are sensitive to PEG-IFN. Four patients treated exclusively with telaprevir were characterized by virus rebound in which predominant high-resistance variants at the end of the monotherapy substitute low-resistance mutants. ${ }^{33}$

In the PROVE 2 trial, breakthrough was found in $8.67 \%$ of patients and relapse in $23.94 \% .{ }^{26}$ Low-resistance mutants were present in 10 out of 22 patients with breakthrough and 35 out of 42 patients with relapse. Any breakthrough related to the longest treatment protocol (T12PR24) is associated with high level resistant variants. These results do not confirm that all resistant variants are sensitive to PEG-IFN. ${ }^{26}$

Viral fitness definition of telaprevir-resistant variants was discussed also in Kuntzen et al. ${ }^{34}$ The authors studied 507 genotype $1 \mathrm{HCV}$-positive treatment-naïve patients. Predominant variants were found in $8.6 \%$ of genotype 1a-infected patients and $1.4 \%$ of genotype $1 \mathrm{~b}$-infected patients. These results show that the concept of viral fitness should be carefully approached in vivo. Viral fitness depends strictly on infection dynamics. As noted, positions 54 and 155 fall in $\mathrm{CD}^{+} \mathrm{T}$ cell epitopes. Therefore, the individual immune response can influence variant fitness and, in parallel, possible removal of compensatory mutations must be considered. ${ }^{34}$

\section{Conclusion and future perspective}

Telaprevir treatment, especially in combination with PEG-IFN and ribavirin, holds promise for chronic HCV infection control. Resistant variants exist and can become predominant also during PEG-IFN and ribavirin combination. These mutants are described as less fit than wild type, and fitness of genotype $1 \mathrm{a}$ and $1 \mathrm{~b}$ differs. Breakthrough and relapse are associated with telaprevir variants and represent a major problem. Better assessment of the protocols and limiting the occurrence of severe adverse events could suggest an increasing role for the resistant variant. Future studies should focus on this area. To date, telaprevir has been used only in genotype 1-infected patients. The application of this antiviral to infected patients of other genotypes will highlight the existence of other mutations and their effects. Future studies should be directed to the compensatory mutations that could explain the predominance of variants in naïve $\mathrm{HCV}$-positive patients and, finally, to a general definition of viral fitness. Viral fitness could be defined by sequencing of the entire viral genome, taking into account all mutations fixed in a certain genome, to study the effect on virus replication.

\section{Acknowledgments}

We would like to thank Mrs Federica M Regini for the editorial assistance and for the English revision.

\section{Disclosures}

The authors report no conflicts of interest.

\section{References}

1. Alter MJ. Epidemiology of hepatitis C virus infection. World J Gastroenterol. 2007;13:2436-2441.

2. Armstrong GL, Wasley A, Simard EP, McQuillan GM, Kuhnert WL, et al. The prevalence of hepatitis C virus infection in the United States, 1999 through 2002. Ann Intern Med. 2006;144:705-714. 
3. Kim WR, Brown RS Jr, Terrault NA, El-Serag H. Burden of liver disease in the United States:summary of a workshop. Hepatology. 2006:36:227-242.

4. Baker DE. Pegylated interferon plus ribavirin for the treatment of chronic hepatitis C. Rev Gastroenterol Disord. 2003;2:93-109.

5. Fried MW, Shiffman ML, Reddy KR, Smith C, Marinos G, et al. Peginterferon alfa-2a plus ribavirin for chronic hepatitis $C$ virus infection. N Engl J Med. 2002;347:975-982.

6. McHutchison JG, Gordon SC, Schiff ER, Shiffman ML, Lee WM, et al. Interferon alfa- $2 \mathrm{~b}$ alone or in combination with ribavirin as initial treatment for chronic hepatitis C. N Engl J Med. 1998;8339: 1485-1492.

7. Bukh J, Miller R, Purcell R. Genetic heterogeneity of hepatitis c virus: quasispecies and genotypes. Semin Liver Dis. 2006;15:41-63.

8. Robertson B, Myers G, Howard C, Brettin T, Bukh J, et al. Classification, nomenclature, and database development for hepatitis $\mathrm{C}$ virus (HCV) and related viruses:proposals for standardization. Arch Virol. 1998;143:2493-2503.

9. Simmonds P, Holmes EC, Cha TA, Chan SW, McOmish F, et al. Classification of hepatitis $\mathrm{C}$ virus into six major genotypes and a series of subtypes by phylogenetic analysis of the NS- 5 region. $J$ Gen Virol. 1993;74:2391-2399.

10. Simmonds P. Genetic diversity and evolution of hepatitis C virus 15 years on. $J$ Gen Virol. 2004;85:3173-3188.

11. Timm J, Roggendorf M. Sequence diversity of hepatitis C virus:implication for immune control and therapy. World J Gastroenterol. 2007;13:4808-4817.

12. Murphy DG, Chamberland J, Dandavino R, Samblon E. A new genotype hepatitis $\mathrm{C}$ virus originating from Central Africa. Hepatology. 2007;46:623A.

13. Gaudieri S, Rauch A, Park LP, Freitas E, Herrmann S, et al. Evidence of viral adaptation to HLA class I-restricted immune pressure in chronic hepatitis C virus infection. J Virol. 2006;80:11094-11104.

14. Manns MP, McHutchison JG, Gordon SC, Rustgi VK, Shiffman M, et al. Peginterferon alfa- $2 \mathrm{~b}$ plus ribavirin compared with interferon alfa-2b plus ribavirin for initial treatment of chronic hepatitis $\mathrm{C}$ : a randomised trial. Lancet. 2001;358:958-965.

15. Strader DB, Wright T, Thomas DL, Seeff LB. Diagnosis, management, and treatment of hepatitis C. Hepatology. 2004;39:1147-1171.

16. Argentini C, Genovese D, Dettori S, Rapicetta M. HCV genetic variability:from quasispecies evolution to genotype classification. Future Microbiol. 2009;4:359-373.

17. Le Guillou-Guillemette H, Vallet S, Gaudy-Graffin S, Payan C, Pivert A, Goudeau A. Lunel-Fabiani Genetic diversity of the hepatitis C virus: impact and issues in the antiviral therapy. World J Gastroenterol. 2007;7:2416-2426.

18. Pawlosky JM, Chevaliez S, McHutchinson JG. The hepatitis C virus life cycle as a target for new antiviral therapies. Gastroenterology. 2007;132:1979-1998.

19. Neuman AU, Lam NP, Dahari H, et al. Hepatitis C virus dynamics in vivo and the antiviral efficacy of interferon alpha therapy. Science. 1998;282:103-107.
20. Simmonds P. Genetic diversity and evolution of hepatitis C virus -15 years on. J Gen Virol. 2004;85:3173-3188.

21. Lin K, Perni RB, Kwong AD, Lin C. VX-950, a novel hepatitis C virus (HCV) NS3-4A protease inhibitor, exhibits potent antiviral activities in HCV replicon cells. Antimicrob Agents Chemother. 2006;50:1813-1822.

22. Reesink HW, Zeuzem S, Weegink CJ, et al. Rapid decline of viral RNA in hepatitis $\mathrm{C}$ patients treated with VX-950:a phase Ib, placebo-controlled, randomized study. Gastroenterology. 2006;131:997-1002.

23. Forestier N, Reesink HW, Weegink CJ, et al. Antiviral activity of telaprevir (VX-950) and peginterferon alfa-2a in patients with hepatitis C. Hepatology. 2007;46:640-648.

24. Lawitz E, Rodriguez-Torres, Muir AJ, et al. Antiviral effects and safety of telaprevir, peginterferon alfa-2a, and ribavirin for 28 days in hepatitis C patients. J Hepatol. 2008;49:163-169.

25. McHutchinson JG, Everson GT, Gordon SC, et al. Telaprevir with peginterferon and ribavirin for chonic HCV genotype 1 infection. N Engl J Med. 2009;360:1827-1838.

26. Hezode C, Forestier N, Duskeido G, Ferenci P, et al. Telaprevir and peginterferon with or without ribavirin for chronic HCV infection. N Engl J Med. 2009;360:1841-1850.

27. Gelderblom HC, Zeuzem S, Weegin CJ, Forestier N, Mcnair L, et al. Inflammatory markers neopterin and alanine aminotransferase in $\mathrm{HCV}$ patients treated with HCV NS3-4A protease inhibitor Telaprevir (VX-950) and/or peginterferon alfa-2a. Scand J Gastroenterol. 2008;43:1122-1127.

28. Lin C, Lin K, Luong Y, Rao BG, Wei Y, et al. In vitro resistance studies of hepatitis C virus serine protease inhibitors, VX-950 and BILN 2061. J Biol Chem. 2004;279:17508-17514.

29. Lin C, Gates CA, Rao BG, Brennan D, Fulghum JR, et al. In vitro studies of cross-resistance mutations against two hepatitis $\mathrm{C}$ virus serine protease inhibitors, VX-950 and BILN 2061. J Biol Chem. 2005;280:36784-36791.

30. Sarrazin C, Kieffer TL, Bartels D, et al. Dynamic hepatitis C virus genotypic and phenotypic changes in patients treated with the protease inhibitor telaprevir. Gastroenterology. 2007;132:1767-1777.

31. Zhou Y, Muh U, Hanzelka BL, Bartels DJ, et al. Phenotypic and structural analyses of hepatitis C virus NS3 protease $\arg ^{155}$ variants. J Biol Chem. 2007;282:22619-22628.

32. Welsch C, Domingues FS, Susser S, Antes I, et al. Molecular basis of telaprevir due to V36 and T54 mutations in the NS3-4 protease of the hepatitis C virus. Gen Biol. 2008;9:R16.

33. Kieffer L, Sarrazin C, Miller JS, et al. Telaprevir and pegylated interferon-alpha-2a inhibit wild-type and resistant genotype 1 hepatitis C virus replication in patients. Hepatology. 2007;46:631-639.

34. Kuntzen T, Timm J, Berical A, et al. Naturally occurring dominant resistance mutations to hepatitis $\mathrm{C}$ virus protease and polymerase inhibitors in treatment-naïve patients. Hepatology. 2008;48: 1769-1778.
Virus Adaptation and Treatment

\section{Publish your work in this journal}

Virus Adaptation and Treatment is an international, peer-reviewed open access journal focusing on the study of virology, viral adaptation and the development and use of antiviral drugs and vaccines to achieve improved outcomes in infection control and treatment. The journal welcomes original research, basic science, clinical \& epidemiological

\section{Dovepress}

studies, reviews \& evaluations, expert opinion and commentary, case reports and extended reports. The manuscript management system is completely online and includes a very quick and fair peer-review system, which is all easy to use. Visit http://www.dovepress.com/ testimonials.php to read real quotes from published authors. 